\title{
Impacts of hydrological restoration on lowland river floodplain plant communities
}

\author{
Daniel R. Richards • Helen L. Moggridge • Philip H. Warren • Lorraine Maltby
}

Received: 22 July 2019/ Accepted: 5 March 2020/Published online: 10 March 2020

(C) The Author(s) 2020, corrected publication 2020

\begin{abstract}
Many lowland floodplain habitats have been disconnected from their rivers by flood defence banks. Removing or lowering these banks can reinstate regular flooding and thus restore these important wetland plant communities. In this study we analyse changes in wetland hydrology and plant community composition following the lowering of flood defence banks at a floodplain of the River Don in the United Kingdom (UK). The aim of the restoration project was to improve the quality of "floodplain grazing marsh" habitat, which is a group of wetland communities that are of conservation interest in the UK. We analyse changes in species richness and community composition over a period of 6 years, and compare the
\end{abstract}

Electronic supplementary material The online version of this article (https://doi.org/10.1007/s11273-020-09717-0) contains supplementary material, which is available to authorized users.

D. R. Richards $(\bowtie)$

Singapore-ETH Centre, ETH Zurich, Singapore,

Singapore

e-mail: richards@arch.ethz.ch

D. R. Richards - P. H. Warren - L. Maltby

Department of Animal and Plant Sciences, The University

of Sheffield, Sheffield, UK

H. L. Moggridge

Department of Geography, The University of Sheffield, Sheffield, UK presence of indicator species from the target floodplain grazing marsh plant communities. The lowering of the flood banks increased the frequency of flood events, from an estimated average of 1.7 floods per year to 571 floods per year. The increased flooding significantly increased the proportion of time that the wetland was submerged, and the heterogeneity in hydrological conditions within the floodplain. There were significant differences in composition between the pre-restoration and restored plant communities. Plants with traits for moisture tolerance became more abundant, although the communities did not contain significantly more 'target' floodplain grazing marsh species at the end of the study period than prior to restoration. Colonisation by floodplain grazing marsh species may have been limited because environmental conditions were not yet suitable, or because of a shortage of colonising propagules. While the desired target plant community has not been achieved after 5 years, it is encouraging that the community has changed dynamically as a result of hydrological changes, and that moisture-tolerant species have increased in occurrence. Over the next few decades, the restored flood regime may cause further environmental change or colonisation events, thus helping increase the occurrence of desired floodplain grazing marsh indicator species.

Keywords Functional trait - Wetland restoration . Hydrological restoration 


\section{Introduction}

Natural floodplains are a threatened habitat in Europe; it has been estimated that up to $90 \%$ of the historical floodplain area has been converted to agricultural or urban use (Tockner and Stanford 2002). Many lowland river floodplains are no longer connected hydrologically to their adjacent floodplains, as flood banks have been constructed to prevent flooding (Jungwirth et al. 2002). The disconnection of rivers and floodplains through flood bank construction has led to degradation of floodplain wetland biodiversity (Tockner and Stanford 2002).

Flooding is important in structuring plant community composition at multiple spatial scales; within habitat patches, across larger mosaics, and between floodplain wetlands at the landscape scale. At the patch scale, the local performance of different species depends on their environmental tolerances and ability to compete with each other (Keddy 1992; Härdtle et al. 2006). Competition and environmental tolerances have interacting effects on performance, because environmental conditions affect the balance of competition between species (Toogood et al. 2008). Species that are highly competitive under dry conditions (referred to here as "competitive specialists" (Grime et al. 1995)) may be negatively affected by flood events; for example if they cannot tolerate root aeration stresses (Gowing \& Spoor 1998), or are easily damaged by flood disturbance (Bornette and Amoros 1996). More frequent flooding may therefore benefit species that are more flood-tolerant, by decreasing competition from competitive specialists (Lenssen et al. 2004). At the scale of floodplain wetland mosaics, spatial variation in flood duration and frequency creates heterogeneity in hydrological conditions. Hydrological heterogeneity enhances the overall biodiversity of floodplain mosaics by maintaining suitable conditions for a diverse range of species with different niches (Junk et al. 1989; Ward et al. 2002). Across floodplain landscapes, flood events allow connectivity between different wetland patches. Flood water can transport plant matter and seeds from habitats elsewhere in the river network (Hölzel and Otte 2001; Gerard et al. 2007), thus adding novel species to the local pool (Moggridge and Gurnell 2010). This process may be important in maintaining the presence of species across a landscape, for example by allowing recolonisation of habitat patches that have been cleared by disturbances (Gurnell et al. 2006).

There is increasing interest in reversing the degradation of floodplains through restoration projects that reconnect rivers and floodplains hydrologically (Zsuffa and Bogardi 1995; Pedersen et al. 2007; Toogood et al. 2008; Schaich et al. 2010; Gonzalez et al. 2015). Such "restoration" projects do not typically aim to reinstate historical communities, as the historical baseline is rarely known and can be hard to define due to long histories of human use (Hilderbrand et al. 2005). Instead, restoration is used as a synonym for altering degraded ecological communities into those that are perceived as more desirable. In the United Kingdom (UK), conservationists have attempted to restore floodplain marshes that are comprised of semi-natural wet grasslands or mire plant communities; these habitats are referred to as floodplain grazing marshes (Mountford 1994; Mountford et al. 2006). Floodplain grazing marsh is found across North-West Europe, and provides habitat to a range of wetland birds, plants, and invertebrates (Mountford et al. 2006). The restoration and creation of floodplain grazing marsh has been a conservation priority for the UK Government for over 20 years (JNCC 1995) and remains of interest for biodiversity conservation and carbon storage (Sozanska-Stanton et al. 2016).

Floodplain restoration projects commonly target particular plant species and communities (Matthews and Spyreas 2010), and aim to create the hydrological conditions that these species require (Wheeler et al. 2004). There are relatively few cases where the impacts of floodplain restoration projects on hydrology and plant community composition have been analysed and documented (Zedler 2000; Schaich et al. 2010). Previous studies have shown that plant communities can shift rapidly following the implementation of restoration strategies (Toogood and Joyce 2008), but that communities often do not develop towards the desired target communities following hydrological restoration, at least over the $\sim 5$ year timespans during which projects are studied (Trowbridge 2007; Matthews and Spyreas 2010). There are several ecological mechanisms which can constrain or alter the trajectory of plant community development (Trowbridge 2007; Matthews and Spyreas 2010). First, the presence of highly competitive species may prevent desirable wetland species from establishing, 
even if hydrological conditions are suitable (Ho and Richardson 2013). Second, there may be environmental factors other than hydrology that impact community composition, such as grazing pressure (Schaich et al. 2010) or nutrient levels (Donath et al. 2003). Finally, desirable species may not be able to rapidly colonise the site by dispersal, even if environmental conditions are suitable for them. This situation may occur if there are few reservoir populations in the river network (Bischoff 2002), meaning that it may take many years for species to establish by dispersal. It can be challenging to disentangle the role of competition, dispersal and environmental filtering mechanisms in constraining or directing trajectories of plant community change (Dawson et al. 2017a). To gain insights into the relative importance of these processes it can be helpful to analyse species performance in relation to functional traits such as dispersal mechanisms, environmental tolerances, and life-history strategies (Pywell 2003; Dawson et al. 2017b).

To inform future floodplain wetland restoration it is important to establish whether flood bank removal can cause changes in hydrology and ecology, and whether these changes are consistent with the desired restoration outcome (Gonzalez et al. 2015; Ockendon et al. 2018). Furthermore, our understanding of the processes underlying observed changes can be improved by analysing the functional traits of the plants present (Gonzalez et al. 2015; Dawson et al. 2017b). This study makes use of a large floodplain wetland restoration attempt initiated in the Humberhead Levels, in the United Kingdom. The floodplain was restored hydrologically by the breaching and lowering of flood banks in 2009, with the aim of enhancing floodplain wetland plant communities. This restoration attempt provides an opportunity to analyse the resulting changes in hydrology and plant community composition. The objectives of this study were (1) analyse the impacts of floodplain restoration on hydrology and plant community composition within the floodplain, over a period of 6 years, (2) analyse the response of plant species to floodplain restoration as a function of their functional traits, and (3) analyse the degree to which the plant communities became more similar to the desired floodplain grazing marsh communities.

\section{Methods}

Overview of the Fishlake restoration project

The Humberhead Levels were once the third largest wetland in England (Rotherham and Harrison 2006), but wetlands in the area have been significantly embanked and drained since 1627 (Gearey et al. 2009; Gaunt 2012). The study floodplain (Fishlake) is located within the Humberhead Levels region along the River Don; a substantial river with a catchment area of over $1,800 \mathrm{~km}^{2}$ (Faulkner and Wass 2005). The location is close to Doncaster, in South Yorkshire in the UK (Latitude: 53.611, Longitude: - 1.002; Fig. 1a). The river level at Fishlake is tidally influenced with a reach of approximately $3.5 \mathrm{~m}$ during spring tides, and $1 \mathrm{~m}$ during neap tides (Hiley et al. 2008). However, the tidal reach is caused by freshwater backing up from the estuary, so is not saline (Hiley et al. 2008). The floodplain extends on both banks of the river, over 25 hectares on the north bank and 22 hectares on the south bank (Fig. 1b). The floodplain has been owned by the Environment Agency-a government agency-since the 1940s (Hiley et al. 2008) and is unusual in having two lines of flood defence; there are low (approximately $5 \mathrm{~m}$ above sea level) flood banks along the riverbank, with more substantial main banks (which are approximately $7 \mathrm{~m}$ above sea level) behind (Fig. 1b). The presence of lower flood defences at Fishlake provided a controlled area in which hydrological connectivity between the river and part of the floodplain could be restored without compromising the main flood defences (Environment Agency 2009). The area between the flood banks has historically been allowed to flood during periods of very high river flow to reduce pressure elsewhere, and is used to graze a herd of approximately 100 beef cattle between March and October (Richards 2014).

The Fishlake floodplain restoration project had a number of vaguely defined target outcomes, including improvement of floodplain grazing marsh habitats, and support of wetland bird biodiversity (Hiley et al. 2008; Richards 2014). Furthermore, the restoration aimed to maintain the presence of existing biodiversity (Richards et al. 2014), and have no negative impact on the suitability of the site for cattle farming (Hiley et al. 2008; Richards 2014). The restoration design aimed to increase the frequency of flood events from between 


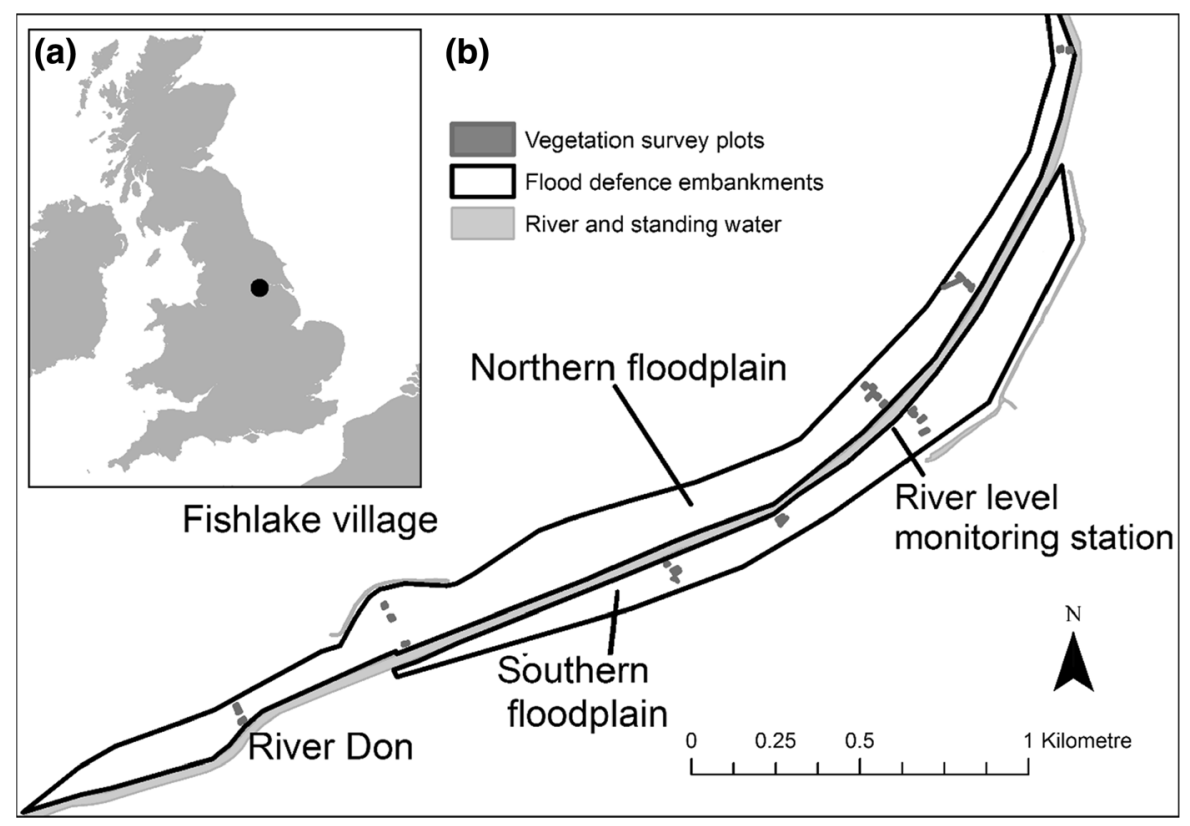

Fig. 1 a Location of the Fishlake floodplain in the UK. b Flood defence banks surrounding the study area. The flood banks on the river side of the floodplain are lower flood banks than those surrounding the landward edge of the floodplain

zero and twelve times a year, to at least thirty-six times a year (Hiley et al. 2008). The low flood banks were further lowered at two locations on the northern bank in August 2009 and the floodplain on the southern bank was reconnected to the river via a culvert in September 2011. Valve culverts were installed to allow flood water to drain from the floodplain relatively quickly after river levels dropped, thereby providing suitable hydrological conditions for floodplain grazing marsh plant species (Hiley et al. 2008).

In addition to the flood bank breaches made at Fishlake, considerable topographic regrading was conducted. A number of existing ditches at the site were dredged and enlarged during June-August in 2009, and in some parts of the site new drainage ditches and pools were dug. To maintain cattle and public access during flood conditions a number of raised banks were added to connect the lower front flood defence banks to the main bank. A "ridge and furrow" pattern of raised banks was added to increase topographic variation and provide refuges for wetland birds during flood events (Environment Agency 2009).
Quantifying the topographic impacts of restoration

The physical changes made during the restoration work at Fishlake were quantified by comparing the topography of the site before and after restoration. High resolution baseline topographic data (scale: 1 pixel $=0.0625 \mathrm{~m}^{2}$ ) were collected as part of the design process in 2009, using airborne light detection and ranging (LIDAR). Comparable topographic data were collected after the restoration work in 2013, using a Leica TCRP1205 robotic theodolite and electronic distance meter. Direct comparison of the flood bank levels and in-floodplain topography allowed the physical impacts of the restoration project to be accurately quantified.

Quantifying the hydrological impacts of restoration

The duration of flood exposure within the floodplain was not quantified prior to restoration. To estimate the hydrological impact of restoration we used logistic regression to predict the submergence of $0.0625 \mathrm{~m}^{2}$ grid squares within the floodplain, as a function of the duration of flooding during the preceding two weeks. Using this model we predicted the percentage of time 
that floodplain grid squares would be submerged, given data on the heights of the flood banks and culverts, and a dataset of river level records collected by the Environment Agency between January 2009 and July 2013. To compare the impacts of restoration on hydrological conditions in the Fishlake floodplain we then ran this model under two scenarios; once using pre-restoration bank heights, and once using the post-restoration bank and culvert heights.

\section{Empirical quantification of flood exposure within the floodplain}

The extent of surface coverage in the floodplain was quantified empirically on 52 occasions between May 2011 and April 2013 (Richards et al. 2014). On each sampling occasion, the points marking the boundaries of each water body were recorded at approximately $10 \mathrm{~m}$ intervals using a Garmin Oregon 450 global positioning system (GPS). These GPS points were then cross-referenced with the high-resolution topographic dataset to estimate the height of the water level in the floodplain. The cross-referencing process generated a number of estimates of the height of the water level in each drainage basin, and the mean of these estimates was taken to represent the water level in each basin on a given survey occasion. The areas that were lower than the estimated water level were then classified as submerged on the sampling occasion. The floodplain was compartmentalised into 12 topographically separate hydrologic sections that act as distinct drainage basins (Richards et al. 2014; Richards 2014), and separate water levels were estimated for each section.

\section{Statistical model of flood exposure within the floodplain}

Flood exposure was modelled at a subset of the $0.0625 \mathrm{~m}^{2}$ grid squares. A regular grid of 1992 squares was selected and hydrological conditions were modelled independently for each grid square. To create a predictive model of floodplain hydrology, the proportional submergence data were linked to a time series of river level data provided by the Environment Agency. River level was monitored at 10 min intervals between the 28th of January 2009 and the 31st of July 2013, near the centre of the course of the river as it passes through the Fishlake floodplain (Fig. 1b). A separate logistic regression model was constructed for each grid square, and submergence (either submerged or not) of the point on each of the 52 sampling occasions was modelled as a binary variable. Submergence was modelled against the proportion of the preceding two weeks that the river water level was higher than the lowest point of the flood defence (i.e. the proportion of time when flooding was occurring). The resulting logistic regression models were then used to predict the relative wetness of each location from a time series of flood events, over the period of the field surveys of flood extent (i.e., between May 2011 and April 2013). Proportional submergence was predicted twice for each location under different conditions; first using flood frequencies calculated using the baseline (2009) flood bank heights, and second using flood frequencies calculated under the restored (2013) flood bank and culvert height conditions.

The statistical hydrological model assumed that the topographic height of each location within the floodplain did not change between the 2009 and 2013 surveys. Locations that changed in height by more than one standard deviation from the mean were therefore excluded from subsequent analyses (565 locations were excluded). A paired t-test was used to test the difference in proportional submergence predicted by the baseline and restored hydrological models. An F test was used to test the difference in variance in the proportional submergence predicted by the baseline and restored hydrological models.

To assess the accuracy of the statistical hydrological model, the predicted post-restoration submergence events were compared to the empirical data. The accuracy of model performance was assessed as the percentage of correctly predicted outcomes.

Plant community changes following restoration

The plant community was first sampled at 28 plots of $100 \mathrm{~m}^{2}$ each prior to any engineering in late June 2009 (Fig. 1). The sampling plots were chosen to represent the range of terrestrial habitats (therefore excluding open water) that were present across the site at that time, and were located in topographically homogenous regions. Plots were square (10 by $10 \mathrm{~m})$ at 14 locations; at the remaining locations the plots were rectangular ( 5 by $20 \mathrm{~m}$ or 3 by $33.3 \mathrm{~m}$ ) to better fit the topography of the site. Plots were clustered into transects for ease of relocation, but transect grouping 
is not considered to have any ecological relevance. Sampling plot locations were recorded using a handheld Garmin E-trex H GPS and a combination of handheld maps, written notes, and photographs. The sample plots were re-surveyed after restoration during late June, in 2011, 2012, 2013, and 2015. In all the surveys, all higher plant taxa were identified and assigned an abundance score on the ordinal DAFOR scale (i.e., dominant, abundant, frequent, occasional, rare), depending on an estimate of coverage within the plot (Brodie 1985). Taxa were generally identified to species level following established field identification guides (Hubbard 1968; Rose 1981). Filamentous algae, Agrostis and Poa grasses were not recorded to species level. To ensure consistency in sampling plot relocation and taxonomy between sampling dates, any new survey staff were first trained by a member of a previous survey team.

Statistical analysis of changes in plant community composition

\section{Changes in species richness and community composition}

Variation in species richness between years was analysed as a repeated measures ANOVA conducted as a linear mixed-effect model using the lme4 $\mathrm{R}$ package (Bates et al. 2013), with statistical significance analysed using the lmerTest $\mathrm{R}$ package (Kuznetsova et al. 2013). The year of the survey was used as an explanatory factor. Post-hoc differences between all pairs of years were analysed using Tukey's Honestly Significant Difference test, as implemented in the multcomp package for $\mathrm{R}$ (Hothorn et al. 2008).

Multivariate differences in composition between the sampled plant communities were visualised using Non-metric multidimensional scaling (NMDS), using the metaMDS function in the vegan package for $\mathrm{R}$ (Oksanen et al. 2012). NMDS was run using a Gower dissimilarity matrix appropriate for ordinal abundance data. Permutational multivariate analysis of variance (non-parametric multivariate analysis of varianceNPMANOVA) of the Gower dissimilarity matrix was used to assess whether the communities were significantly different between all pairs of years. This procedure was carried out using the adonis function in the vegan R package (Oksanen et al. 2012), with the distance matrix modelled as a function of year, stratified by sample plot. A global NPMANOVA was first carried out, followed by pairwise comparisons between each consecutive set of years, using a Bonferroni-adjusted significance level $(\mathrm{p}<0.005)$. For visualisation, species were plotted with different colour symbols depending on whether they were moisture tolerant, defined as whether the species is associated with an Ellenberg M scoresof at least seven (Hill et al 1999).

Response of taxa as a function of their functional traits

To investigate the responses of the plant communities to increased flooding in more detail, we modelled the performance of individual taxa as a function of three functional traits; moisture tolerance (from Ellenberg 1988), competitive specialisation and ruderal specialisation (from Grime et al. 1995). A final functional trait, the stress tolerance index from Grime et al. (1995), was excluded because it is the inverse of the sum of the competitor and ruderal indices, so including this variable would create a singular model. The competitive specialisation and ruderal specialisation indices are measured on a scale of 0 to 1 , while moisture tolerance is defined as a binary variable where moisture tolerant species have Ellenberg $\mathbf{M}$ scores of at least seven, indicating that they are tolerant of at least constant dampness or moisture (Hill et al 1999). We used a threshold Ellenberg M score rather than the original ordinal scale because the range of soil moisture conditions created by the restoration work was very large-ranging from open water to occasionally flooded grassland (Richards 2014). In contrast to the competitive and ruderal specialisations, we were concerned with whether the plant species had tolerance to any of the soil moisture conditions present due to the restoration, rather than whether or not they were more highly specialised to the most moist conditions, as would be indicated if we had treated the index as a linear scale.

Ordinal regression was used to model the number of DAFOR abundance classes that each species moved up or down between the baseline and restored surveys at each sampling plot. The highest possible increase in abundance (from Rare to Dominant) would thus be recorded as a change in abundance of +4 classes, while the greatest possible decline in abundance (from Dominant to Rare) would be modelled as a -4 
abundance classes. Using ordinal regression, an increase of four abundance classes was modelled as a greater change than an increase of three classes, but the magnitude of change between an increase of one or two classes is not necessarily linear. The performance of each species was modelled at all survey plots, and both species and survey plot were included as random effects (with random intercepts for both species and plot) to account for pseudoreplication. Ordinal regression models were constructed as cumulative link mixed models using the ordinal $\mathrm{R}$ package (Christensen 2013).

\section{Quantifying development towards the target communities}

The development towards the target floodplain grazing marsh plant communities was analysed as the number of floodplain grazing marsh indicator species present in the sampled communities. Floodplain grazing marsh is a broad habitat type of which there are a number of desirable target communities (Mountford et al. 2006), so desirability was analysed as the maximum similarity to a pool of National Vegetation Classification (NVC) community types that have previously been defined as floodplain grazing marsh. Mountford et al. (2006) identify 40 NVC subcommunities as floodplain grazing marsh, but three of these community types have not been recorded within $100 \mathrm{~km}$ of Fishlake, so were excluded from the analysis as they were assumed to be unlikely to establish.

To analyse the similarity of the sampled communities to the 37 target NVC communities, "ideal" floodplain grazing marsh communities were generated. Floodplain grazing marsh communities were simulated by randomly drawing species from the possible species pool, using the species richness and frequency of occurrence data contained in the NVC (Rodwell 1991, 1992, 1995). Fifty communities were for each of the 37 NVC community types.

The similarity of each sampled community to each simulated community was was measured as the proportion of the simulated target community that were present in the community, with a correction for the number that would be expected to match by chance given the numbers of species involved. This index was calculated according to the equation;
$C=\frac{M-\left(\frac{S}{T} \times F\right)}{S}$

where $C$ was the corrected similarity, $M$ was the number of matched species, $S$ was the number of species present in the simulated target community, $T$ was the total number of species present in the dataset (i.e. 1432), and $F$ was the number of species present in the Fishlake sample.

The similarity of each sampled community to each NVC community was quantified as the mean of the 50 simulated community replicates, and the score for the NVC community type that the sample was most similar to was taken as the index of similarity to the target of floodplain grazing marsh. The maximum possible similarity index was one, which would indicate that all floodplain grazing marsh indicator species were present. The minimum possible similarity was zero, indicating that no floodplain grazing marsh indicator species were present.

Temporal changes in similarity to the target floodplain grazing marsh communities were analysed as a repeated measures ANOVA conducted as a linear mixed-effect model using the lme4 $\mathrm{R}$ package (Bates et al. 2013), with statistical significance analysed using the lmerTest $\mathrm{R}$ package (Kuznetsova et al. 2013). The year of the survey was used as an explanatory factor. Post-hoc differences between all pairs of years were analysed using Tukey's Honestly Significant Difference Post-hoc test, as implemented in the multcomp package for R (Hothorn et al. 2008).

\section{Results}

Topographic changes following restoration

Comparison of the pre- and post-restoration topography indicates that two locations on the northern bank were significantly lowered during restoration to allow more frequent flooding (Fig. 2). At each location an eight metre section of the lower flood bank was lowered by approximately $1.5 \mathrm{~m}$ (from 5.3 to $3.7 \mathrm{~m}$ ). The $0.5 \mathrm{~m}$ diameter culvert added under the southern bank was approximately $2.5 \mathrm{~m}$ above sea level (approximately $2.5 \mathrm{~m}$ below the top of the flood bank) (Fig. 2). The waterbodies in the Fishlake floodplain were substantially lower following restoration, particularly in the centre of the northern floodplain, and at 


\section{Change in topography between 2009 and 2013}



Fig. 2 Changes in topographic height of the Fishlake floodplain between 2009 and 2013. Purple shades indicate areas where the topography was raised during the restoration works, green

the constructed pond at the eastern end of the southern bank (Fig. 2). The largest areas where topographic height was increased were a new ridge and furrow system and island on the northern bank, and a bank designed to allow cattle access that was adjacent to the new pond on the southern bank (Fig. 2).

Hydrological modelling and hydrological impacts of restoration

When compared to the empirical data, the statistical hydrological model predicted the correct outcome in $87 \%$ of cases. Submerged cases were correctly predicted $90 \%$ of the time, while unsubmerged cases were correctly predicted $75 \%$ of the time. This suggests that the hydrological model slightly overestimated the probability of locations being flooded. The effect of this estimation should be consistent between the 2009 and 2013 models, so comparing the predictions from these models should still allow relative differences in wetness to be assessed.

The lower flood bank was approximately $5.3 \mathrm{~m}$ high prior to restoration, and at this height the floodplain would have experienced eight flood events between January 28, 2009 and July 31, 2013 (an shades indicate areas that were lowered. Beige indicates areas of negligible change. For references to colour please see the online version of this article

average of 1.7 floods per year). The median duration of flood events would have been $16.5 \mathrm{~h}$, and the longest flood would have been approximately 2 days. With the bank breaches lowered to a height of $3.7 \mathrm{~m}$, an estimated 571 flood events would have occurred over the study period. This is an average of 11 flood events every month. The median duration of a flood event would have been $50 \mathrm{~min}$, and the longest flood event would have lasted for approximately five days.

The restored hydrological model predicted that the floodplain would be submerged for a significantly greater proportion of the time than the baseline hydrological model $(\mathrm{t}=33.4, \mathrm{df}=1428, \mathrm{p}<0.001)$. On average the restored floodplain was predicted to be submerged for an additional $9 \%$ of the time compared to the baseline model. The difference in proportional submergence predicted by the baseline and restored models varied spatially, with the southern bank of the floodplain in particular showing a large increase in the proportion of time that it was submerged (Fig. 3). The restored hydrological model predicted significantly greater spatial variation in hydrological conditions than the baseline model $(\mathrm{F}=0.36, \mathrm{df}=1428$, $\mathrm{p}<0.001)$. 


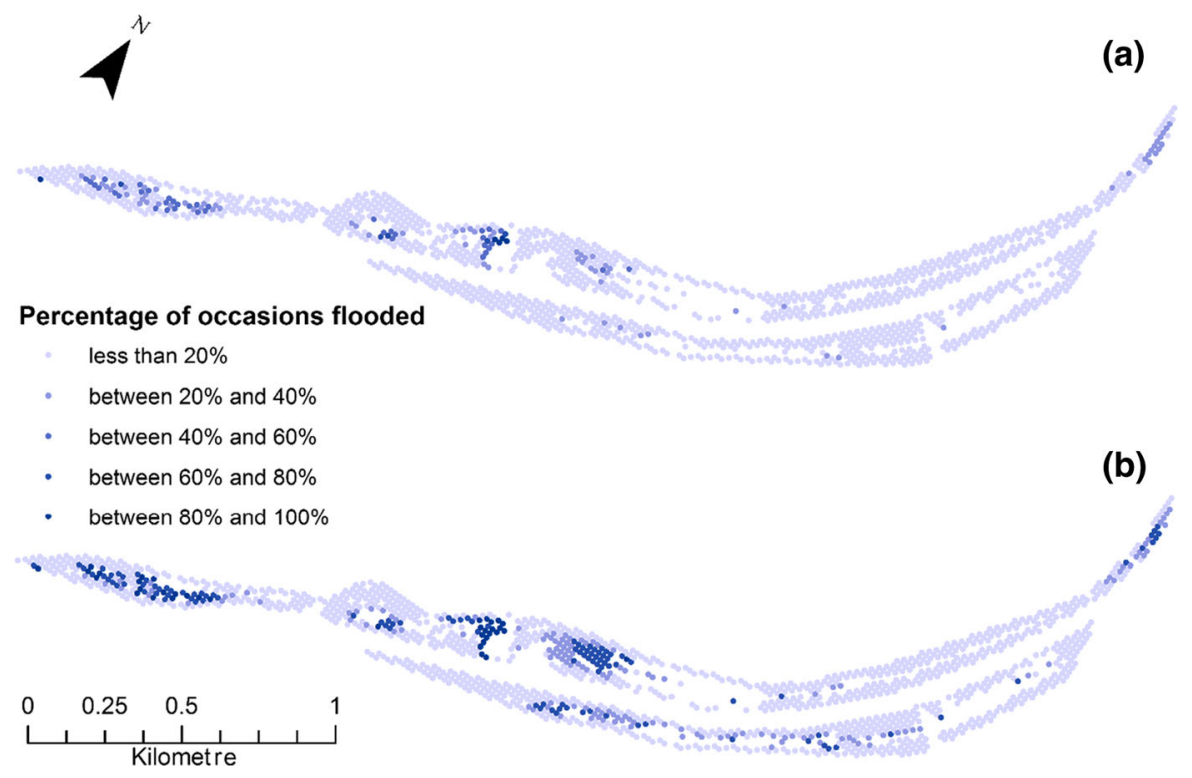

Fig. 3 Percentage flood exposure of the Fishlake floodplain modelled under baseline and restored flooding scenarios. a Flood exposure under the 2009 baseline flood bank levels. b Flood exposure modelled using the 2013 restored flood bank levels. Only floodplain areas that did not experience significant

Changes in plant community composition

following restoration

The species richness of the sampled plant communities differed significantly between survey years $(\mathrm{F}=4.4, \mathrm{df}=108, \mathrm{p}=0.002$; Fig. 4; mean values; $2009=12.79, \quad 2011=15.79, \quad 2012=13.25$, $2013=13.04,2015=13.82)$. The species richness increased significantly between 2009 and 2011 ( $\mathrm{z}=3.7, \mathrm{p}=0.002$ ) but was significantly lower in $2012(\mathrm{z}=-3.1, \quad \mathrm{p}=0.02)$ and $2013 \quad(\mathrm{z}=-3.4$, $p=0.007)$ than in 2011. No other pairwise comparisons between years were statistically significant following the post-hoc test. Twenty-eight species that were not recorded in 2009 were recorded in later years, including a number of aquatic species such as Callitriche stagnalis and Potamogeton natans, and wet grassland species such as Eleocharis palustris and Carex spicata (Supplementary Information Appendix $1)$.

Ordination of the plant community data revealed that the pre-restoration (2009) communities were noticeably distinct from the communities surveyed in all post-restoration years (Fig. 5a). The communities were significantly dissimilar depending on year changes in local topography are shown. Submergence was modelled from a time series of river level data between May 2011 and May 2013. Darker blue areas indicate more frequently submerged areas. For colour version please see the online version of this article

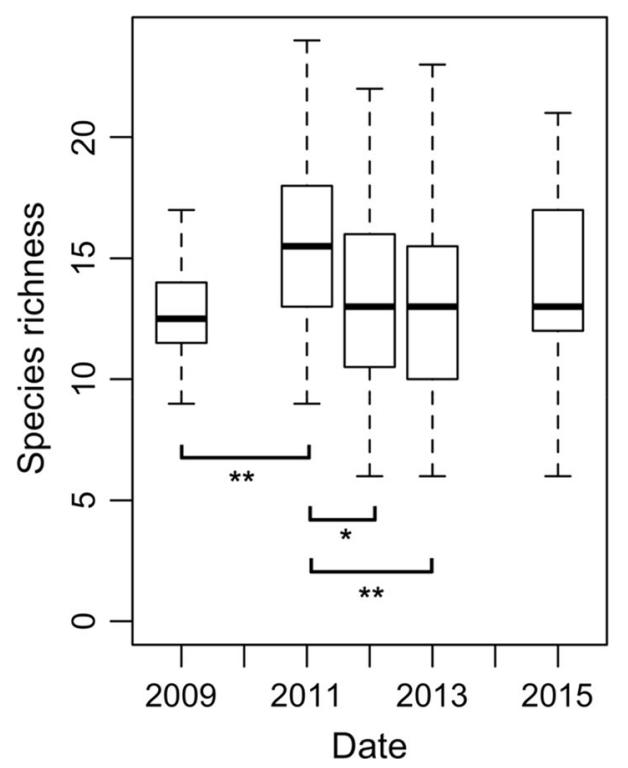

Fig. 4 Species richness in 28 sampled quadrats on 5 survey occasions. Box and whisker plots show the median (bold line), interquartile range (box), and range within $1.5 \times \mathrm{IQR}$ (whiskers). Number of asterisks indicate the level of post-hoc significance in differences between connected pairs of years $(* \mathrm{p}<0.05, * * \mathrm{p}<0.01, * * * \mathrm{p}<0.001)$ 


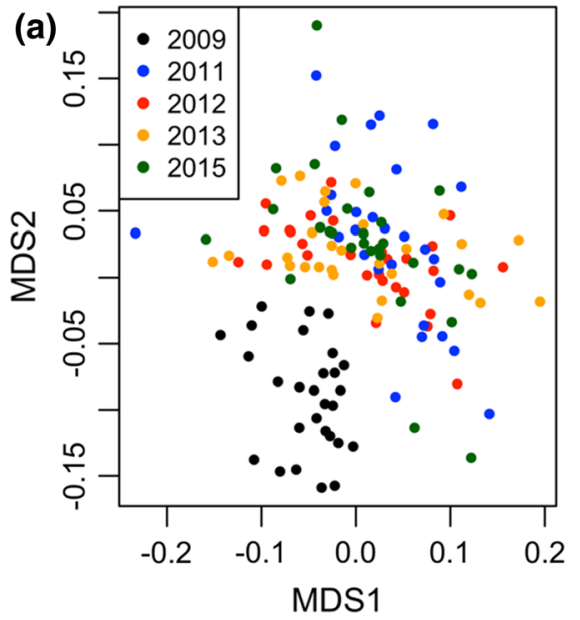

Fig. 5 Non-metric multidimensional scaling of plant community data collected on five occasions. a Community similarities ordinated for quadrats recorded in different years. b Species scores coloured by the moisture tolerance of the species. Eigenvalues for DCA Axis 1 and 2 were 0.32 and 0.19

$\left(\mathrm{F}=7.6, \mathrm{R}^{2}=0.18, \mathrm{p}=0.001\right)$, and all pairs of years were significantly different following the Bonferronicorrected post-hoc procedure (maximum $\mathrm{p}=0.002$ ). The performance of individual taxa was significantly affected by their functional traits (Table 1), and the first axis of the NMDS was negatively associated with moisture tolerant taxa (Fig. 5b). Examples of moisture tolerant species with high scores for the first NMDS axis include Glyceria fluitans, Juncus effusus, Juncus inflexus, and Persicaria amphibia (Supplementary Information Appendix 1).

Moisture tolerant plants were more likely than nonmoisture tolerant plants to increase in abundance or colonise survey plots (Table 1), while taxa with stronger ruderal traits were more likely to decline in abundance or go locally extinct (Table 1). The competitive ability of the taxa had no significant effect on their performance (Table 1). Species that

Table 1 Cumulative logit mixed effects model for the performance of plant taxa modelled as a function of three functional traits

\begin{tabular}{llllr}
\hline Variable & Coefficient & SE & z & \multicolumn{2}{l}{$p$} \\
\hline Competitor score & -0.03 & 0.01 & -1.9 & 0.056 \\
Ruderal score & -0.22 & 0.11 & -2.0 & 0.040 \\
Moisture tolerance & 0.27 & 0.08 & 3.4 & $<0.001$ \\
\hline
\end{tabular}

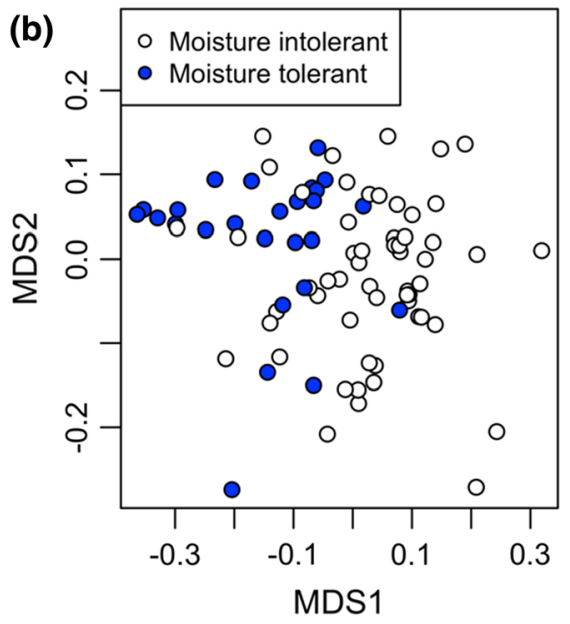

respectively. Moisture tolerant species were defined as those with Ellenberg Moisture tolerance values of greater than or equal to 7. For colour version please see the online version of this article

showed large increases in abundance between sequential years at several survey plots included Poa spp., Festuca rubra, Alopecurus geniculatus, Cirsium vulgare, Ranunculus repens, and Ranunculus acris. Species that showed large declines in abundance between sequential years at several survey plots included Elymus repens, Agrostis spp., Alopecurus geniculatus, Lolium perenne, Deschampsia cespitosa, and Glyceria fluitans.

There was significant variation in the similarity of the surveyed plant communities to the target floodplain grazing marsh communities between years $(\mathrm{F}=3.31, \mathrm{df}=107.27, \mathrm{p}=0.01$; Fig. 6; mean values; $2009=0.15,2011=0.12,2012=0.15,2013=0.15$, $2015=0.15)$. The similarity to floodplain grazing marsh increased significantly between 2011 and 2012 $(\mathrm{z}=2.91, \mathrm{p}=0.03$; Fig. 6 ), and increased between 2011 and 2013 ( $z=3.32, p=0.01$; Fig. 6). No other pairwise comparisons between years were statistically significant following the post-hoc test.

\section{Discussion}

Hydrological and plant community change followed topographic restoration

Floodplain restoration projects are commonly designed to increase flood exposure and heterogeneity 


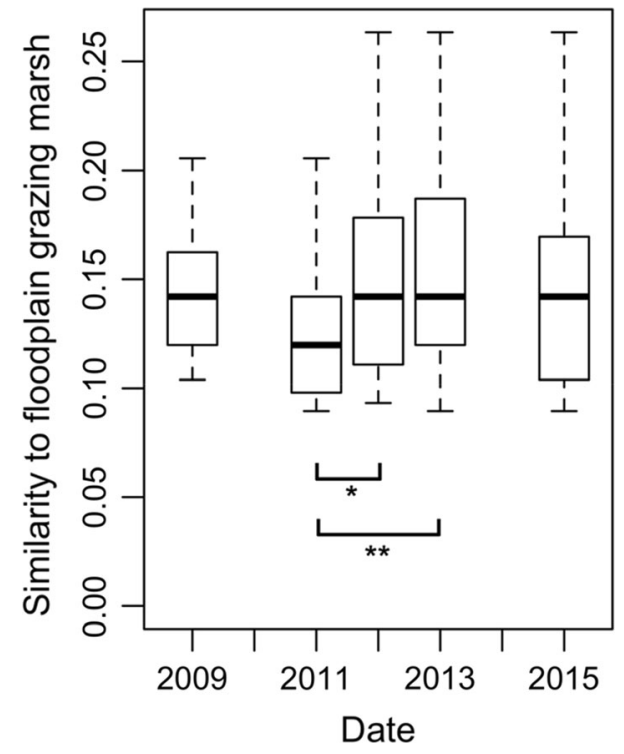

Fig. 6 Similarity of sampled communities to target floodplain grazing marsh communities. Box and whisker plots show the median (bold line), interquartile range (box), and range within $1.5 \times$ IQR (whiskers). Similarity is quantified as the maximum number of species that were present in the sample that were also present in a simulated floodplain grazing marsh target community. Possible range of similarity index is between zero and one. Number of asterisks indicate the level of post-hoc significance in differences between connected pairs of years $(* p<0.05$, ** $\mathrm{p}<0.01, * * * \mathrm{p}<0.001)$

in habitat conditions within floodplain wetlands (Zsuffa and Bogardi 1995; Hammersmark et al. 2005; Rohde et al. 2006), but there are few studies where surface hydrology has been monitored in detail following restoration (Acreman et al. 2007). The Fishlake floodplain experienced significant changes in hydrological conditions as a result of the physical alterations that were made to the site during the restoration project. The increased connectivity between the river and floodplain resulted in an increase in the frequency and duration of flood events, thus increasing the percentage of time that the floodplain surface was submerged. The hydrological impacts of restoration varied spatially depending on the height of the nearest flood bank breach or culvert and the local topography, resulting in greater spatial heterogeneity in hydrological conditions.

The plant communities at the Fishlake floodplain were highly dynamic, with significant differences in Gower dissimilarity based on occurrence and relative abundance observed between all pairs of consecutive surveys. The largest change in plant community composition occurred immediately following restoration, between the surveys in 2009 and 2011. While the changes in community composition in later years were significant, the magnitude of change was smaller, and the trajectory of change was not consistent between consecutive years. As a result, the communities sampled in 2011, 2012, 2013, and 2014 fell close together in NMDS space (Fig. 5a). The observed rapid change in plant community composition is consistent with previous studies using translocation experiments and space-for-time substitution, which have found rapid changes in community composition following changes in hydrological conditions (Toogood et al. 2008; Toogood and Joyce 2009).

Plants face trade-offs in developing traits that enable different life history strategies, so plants with enhanced ruderal abilities (those able to survive in high disturbance areas) typically have reduced tolerances to stressors such as soil moisture (Grime 1977). Under the drier conditions observed at Fishlake prior to restoration, plants with ruderal specialisations held an advantage due to disturbance caused by grazing cattle. However, ruderal plants suffered reduced fitness after the restoration of flooding and consequently declined in abundance, probably because they lacked traits for moisture tolerance. Conversely, moisture tolerant species were able to take advantage of the suitable environmental conditions and reduced competition after flooding was restored, so increased in abundance (Goldberg 1996; Lenssen et al. 2004).

At Fishlake, the rapid rate of change in community composition can be partly explained by declines in the abundance of taxa with low moisture tolerance, as these taxa may have been susceptible to local extinction during the first major flood event. However, the species richness recorded in quadrats at Fishlake remained relatively stable throughout the study years, and even increased between 2009 and 2011, indicating that moisture tolerant taxa were able to increase in abundance and colonise quadrats fairly rapidly. Moisture tolerant species were able to take advantage of the reduced competition rapidly after restoration either because persistent seedbanks were present (Geertsema et al. 2002; Gurnell et al. 2006; Rosenthal 2006), because of short-distance propagule dispersal from other areas of the floodplain by flood water, wind, or animals (Merritt and Wohl 2006; Rosenthal 2006), or because individuals spread vegetatively within or into quadrats (McDonald 2001). 
Plant communities did not develop

towards the target of floodplain grazing marsh

Despite the significant changes in plant community composition and increased abundance of moisturetolerant taxa, the Fishlake communities did not become more similar to floodplain grazing marsh, which was the desired target of restoration. Stochasticity between the surveys appears to have prevented a consistent trajectory of change developing between 2011 and 2015, as these surveys were grouped together in the NMDS space (Fig. 5a) (Trowbridge 2007; Matthews and Spyreas 2010). However, even the large change in composition between 2009 and 2011 did not result in a significant increase in the number of floodplain grazing marsh species that were present. Throughout all years, the communities were fairly dissimilar to floodplain grazing marsh; approximately half of the species present in the sample quadrats during all surveys were floodplain grazing marsh indicators (Figs. 4 and 6).

Previous work has shown that restoration of hydrological connectivity between rivers and floodplains often does not result in widespread colonisation by desirable species, at least over the first 20 years (Donath et al. 2003; Bissels 2004; Rosenthal 2006; Gerard et al. 2007). It is therefore not surprising that the communities at Fishlake did not become significantly more similar to the target communities. In some cases the lack of colonisation by desirable species has been attributed to dispersal limitation (Bissels 2004), although in other examples the reasons remain unclear (Gerard et al. 2007). Colonisation by floodplain grazing marsh species may have been limited at Fishlake if environmental conditions were not suitable for the species to establish (Eriksson and Ehrlén 1992). In addition to hydrological factors, legacy effects of past land use can constrain restoration trajectories (Dawson et al. 2017b, 2017a). It is possible that high nutrient levels as a result of agricultural improvement (Donath et al. 2003) or disturbance caused by cattle grazing (Schaich et al. 2010) limited the establishment of floodplain grazing marsh indicators. However, many desirable floodplain grazing marsh species have relatively wide environmental tolerances (Mountford et al. 2006) and are commonly found in improved, grazed grasslands similar to the Fishlake floodplain (Crofts and Jefferson 1999; Hiley et al. 1998).
An alternative explanation for the lack of colonisation by floodplain grazing marsh indicator species is that colonisation was limited by a low rate of dispersal of new species. The dispersal of plant propagules by flood events depends partly on the frequency and spatial characteristics of flood flow. In contrast to bankside riparian habitats, in which flow-mediated dispersal can play an important role in maintaining species distributions (Nilsson et al. 1991), floodplains are not continuously connected hydrologically to watercourses (Reckendorfer et al. 2006), so opportunities for dispersal may be less constant. The deposition of propagules by flooding can also be spatially patchy, as the greatest numbers are typically deposited at strandlines (Vogt 2004) where flood debris accumulates. Strandlines, particularly those left after larger flood events, are likely to be located at topographic high points. Higher areas may drain more rapidly and be exposed to less frequent flooding, so may not be the most suitable areas of habitat for propagules of wet grassland or marsh plants. Patchily distributed propagules may eventually be dispersed evenly over a floodplain area, but the delay and resulting desiccation can increase propagule mortality (Merritt and Wohl 2006). Colonising propagule densities may be particularly low if there are few suitable source populations nearby (Bissels 2004). The River Don and its associated catchment are highly modified (Shaw, 2012), so patches of floodplain grazing marsh or other wetland habitats may now be rarer in the network than they were historically (Buijse et al. 2002). However, significant wetlands still exist in the vicinity, including a National Nature Reserve at Thorne Moors (Gaunt 2012). To improve the viability of colonisation following future restoration attempts in the Humberhead Levels, practitioners should consider the position of the site in the river catchment, and the functional connectivity to suitable source populations.

Future suggestions for restoration at Fishlake

The relative importance of different drivers in constraining restoration success at Fishlake remains unclear. Future management actions at the site may therefore target a range of strategies, with the hope that some combination of changes may facilitate further success in encouraging floodplain grazing marsh indicator species. The site remains relatively heavily grazed, causing disturbance to plant communities and 
continuing to deposit high nutrient levels (Richards 2014). Future reductions in herd size could reduce the impacts of grazing, or exclusion fences could be used to allow more sensitive vegetation to develop in some parts of the wetland (Schaich et al. 2010). Connectivity to neighbouring wetlands may be hard to improve in the short term. As an alternative, propagules of desirable plant species could be manually brought onto the site, to facilitate colonisation (McKinstry and Anderson 2003).

Wetland restoration attempts typically set goals or targets, which are often related to the plant community and articulated as sets of reference communities or exemplar sites (Bernhardt et al. 2007; Matthews and Spyreas 2010). Given the complexities of reaching such goals (Trowbridge 2007; Matthews and Spyreas 2010) and the difficulties in knowing how to set them (Hughes et al. 2011, 2012), it has been suggested that a more openended approach to restoration may be more appropriate, and that restoration success could also be measured by other indices (Hughes et al. 2011, 2012). While the interventions made at Fishlake have not yet created a plant community that is more similar to the target, there has nonetheless been a significant shift in community composition. Furthermore, the increase in flood frequency at the site has had implications for other aspects of biodiversity, and may impact ecosystem services including recreation, flood water regulation, and food provision (Jessop et al. 2015; Richards et al. 2018; Richards 2014).

\section{Conclusions}

The restoration of hydrological connectivity in floodplains can alter hydrological conditions and have a substantial effect on plant community composition. In this case study, plant community composition changed dynamically over a relatively short period. However, the plant community did not develop towards the desired floodplain grazing marsh community types, and the trajectory of change appeared to be constrained by a lack of colonisation by floodplain grazing marsh species. A lack of colonisation may be due to unsuitable environmental conditions or shortage of propagules in the wetland network. While the desired plant community has not yet been reached at Fishlake, the hydrological impacts of restoration will continue to alter environmental conditions over the coming years. Future changes brought about by flooding may act to create more suitable environmental conditions for floodplain grazing marsh species, or allow colonisation by new species from elsewhere in the river system.

Acknowledgements This study was supported by a UK Natural Environment Research Council Ph.D. studentship to D.R.R. (reference number NE/ 1528593/1). We thank Phil Eades, Nichola Marshall and Philip Richards for field assistance and the Environment Agency for their support of the research and permission to work at Fishlake. We also thank the reviewers and editor for their constructive feedback which greatly improved the work.

Funding This study was supported by a UK Natural Environment Research Council Ph.D. studentship to D.R.R. (reference Number NE/1528593/1). We thank Phil Eades, Nichola Marshall and Philip Richards for field assistance and the Environment Agency for their support of the research and permission to work at Fishlake.

Open Access This article is licensed under a Creative Commons Attribution 4.0 International License, which permits use, sharing, adaptation, distribution and reproduction in any medium or format, as long as you give appropriate credit to the original author(s) and the source, provide a link to the Creative Commons licence, and indicate if changes were made. The images or other third party material in this article are included in the article's Creative Commons licence, unless indicated otherwise in a credit line to the material. If material is not included in the article's Creative Commons licence and your intended use is not permitted by statutory regulation or exceeds the permitted use, you will need to obtain permission directly from the copyright holder. To view a copy of this licence, visit http://creativecommons. org/licenses/by/4.0/.

\section{References}

Acreman MC, Fisher J, Stratford CJ et al (2007) Hydrological science and wetland restoration: some case studies from Europe. Hydrol Earth Syst Sci 11:158-169

Bates D, Maechler M, Bolker B, Walker S (2013) lme4: linear mixed-effects models using Eigen and S4. R package version 1.0-5. https://CRAN.R-project.org/package=lme4

Bernhardt ES, Sudduth EB, Palmer MA et al (2007) Restoring rivers one reach at a time: results from a survey of U.S. River Restor Practitioners Restor Ecol 15:482-493

Bischoff A (2002) Dispersal and establishment of floodplain grassland species as limiting factors in restoration. Biol Conserv 104:25-33

Bissels S (2004) Evaluation of restoration success in alluvial grasslands under contrasting flooding regimes. Biol Conserv 118:641-650 
Bornette G, Amoros C (1996) Disturbance regimes and vegetation dynamics : role of floods in riverine wetlands. J Veg Sci 7:615-622

Brodie J (1985) Vegetation analysis. Grassland studies. George Allen \& Unwin, Boston, pp 7-9

Buijse AD, Coops H, Staras M et al (2002) Restoration strategies for river floodplains along large lowland rivers in Europe. Freshw Biol 47:889-907

Crofts A, Jefferson RG (1999) The lowland grassland management handbook (2nd Edition). English Nature and The Wildlife Trusts

Christensen RHB (2013) Ordinal-regression models for ordinal data R package version 2013.9-30. https://www.cran.rproject.org/package $=$ ordinal $/$

Dawson SK, Kingsford RT, Berney P, Catford JA, Keith DA, Stoklosa J, Hemmings FA (2017a) Contrasting influences of inundation and land use on the rate of floodplain restoration. Aquat Conserv Mar Freshw Ecosyst 27:663-674

Dawson SK, Warton DI, Kingsford RT, Berney P, Keith DA, Catford JA (2017b) Plant traits of propagule banks and standing vegetation reveal flooding alleviates impacts of agriculture on wetland restoration. J Appl Ecol 54:1907-1918

Donath TW, Holzel N, Otte A (2003) The impact of site conditions and seed dispersal on restoration success in alluvial meadows. Appl Veg Sci 6:13-22

Ellenberg H (1988) Vegetation ecology of central Europe, 4th edn. Cambridge University Press, Cambridge

Agency E (2009) Fishlake habitat creation scheme environmental report. Leeds, Environment Agency

Eriksson AO, Ehrlén J (1992) Seed and microsite limitation of recruitment in plant populations. Oecologia 91:360-364

Faulkner D, Wass P (2005) Flood estimation by continuous simulation in the Don catchment, South Yorkshire, UK. Water Environ J 19:78-84

Gaunt G (2012) A review of large-scale man-made river and stream diversions in the Humberhead Region. Yorksh Archaeol J 84:59-76

Gearey BR, Marshall P, Hamilton D (2009) Correlating archaeological and palaeoenvironmental records using a Bayesian approach: a case study from Sutton Common, South Yorkshire, England. J Archaeol Sci 36:1477-1487

Geertsema W, Opdam P, Kropff MJ (2002) Plant strategies and agricultural landscapes: survival in spatially and temporally fragmented habitat. Landsc Ecol 17:263-279

Gerard M, El Kahloun M, Mertens W et al (2007) Impact of flooding on potential and realised grassland species richness. Plant Ecol 194:85-98

Goldberg DE (1996) Competitive Ability: Definitions, Contingency and Correlated Traits. Philos Trans R Soc B 351:1377-1385

Gonzalez E, Sher AA, Tabacchi E, Masip A, Poulin M (2015) Restoration of riparian vegetation: a global review of implementation and evaluation approaches in the international, peer-reviewed literature. $J$ Environ Manage 158:85-94

Gowing DJG, Spoor G (1998) The effect of water table depth on the distribution of plant species on lowland wet grassland. In: Bailey RG, José PV, Sherwood BR (eds) United Kingdom floodplains. Westbury, Otley, pp 185-196
Grime JP (1977) Evidence for the existence of three primary strategies in plants and its relevance to ecological and evolutionary theory. Am Nat 111:1169-1194

Grime JP, Hodgson JG, Hunt R (1995) The abridged comparative plant ecology. Chapman and Hall, London

Gurnell AM, Boitsidis AJ, Thompson K, Clifford NJ (2006) Seed bank, seed dispersal and vegetation cover : colonization along a newly-created river channel. J Veg Sci 17:665-674

Hammersmark CT, Fleenor WE, Schladow SG (2005) Simulation of flood impact and habitat extent for a tidal freshwater marsh restoration. Ecol Eng 25:137-152

Härdtle W, Redecker B, Assmann T, Meyer H (2006) Vegetation responses to environmental conditions in floodplain grasslands: prerequisites for preserving plant species diversity. Basic Appl Ecol 7:280-288

Hilderbrand RH, Watts AC, Randle AM (2005) The myths of restoration ecology. Ecol Soc 10:19

Hiley P, Hillman J, Hughes C, Potter A (2008) Fishlake wetland and river habitat improvement feasibility study. Report produced by Scott Wilson Consultancy for the Environment Agency

Hill MO, Mountford JO, Roy DB, Bunce RGH (1999) Ellenberg's indicator value for British plants. ECOFACT volume 2 Technical Annex. Institute of Terrestrial Ecology, Huntingdon

Ho M, Richardson CJ (2013) A five year study of floristic succession in a restored urban wetland. Ecol Eng 61:511-518

Hölzel N, Otte A (2001) The impact of flooding regime on the soil seed bank of flood-meadows. J Veg Sci 12:209-218

Hothorn T, Bretz F, Westfall P (2008) Simultaneous inference in general parametric models. Biometric J 50:346-363

Hubbard CE (1968) Grasses: a guide to their structure, identification, uses, and distribution in the British Isles. Penguin Books, London

Hughes FMR, Adams WM, Stroh PA (2012) When is openendedness desirable in restoration projects? Restor Ecol 20:291-295

Hughes FMR, Stroh PA, Adams WM, Kirby KJ, Mountford JO, Warrington S (2011) Monitoring and evaluating largescale, "open-ended" habitat creation projects: a journey rather than a destination. J Nat Conserv 19:245-253

Jessop J, Spyreas G, Pociask GE, Benson TJ, Ward MP, Kent AD, Matthews JW (2015) Tradeoffs among ecosystem services in restored wetlands. Biol Conserv 191:341-348

JNCC (1995) Biodiversity: the UK steering group report volume 2: action plans. Joint Nature Conservation Committee of the United Kingdom, Peterborough

Jungwirth M, Muhar S, Schmutz S (2002) Re-establishing and assessing ecological integrity in riverine landscapes. Freshw Biol 47:867-887

Junk WJ, Bayley PB, Sparks RE (1989) The flood pulse concept in river-floodplain systems. Can J Fish Aquat Sci 106:110-127

Keddy PA (1992) Assembly and response rules: two goals for predictive community ecology. J Veg Sci 119:345-364

Kuznetsova A, Brockhoff PB, Christensen RHB (2013) lmerTest: tests for random and fixed effects for linear mixed effect models. $\mathrm{R}$ package version 2.0-3. https:// CRAN.R-project.org/package=lmerTest 
Lenssen JPM, van de Steeg HM, de Kroon H (2004) Does disturbance favour weak competitors? Mechanisms of changing plant abundance after flooding. J Veg Sci 15(305):314

Matthews JW, Spyreas G (2010) Convergence and divergence in plant community trajectories as a framework for monitoring wetland restoration progress. J Appl Ecol 47(5):1128-1136

McDonald AW (2001) Succession during the recreation of a flood-meadow 1985-1999. Appl Veg Sci 4:167-176

McKinstry MC, Anderson SH (2003) Improving aquatic plant growth using propagules and topsoil in created bentonite wetlands of Wyoming. Ecol Engin 21:175-189

Merritt DM, Wohl EE (2006) Plant dispersal along rivers fragmented by dams. River Res Appl 22:1-26

Moggridge HL, Gurnell AM (2010) Hydrological controls on the transport and deposition of plant propagules within riparian zones. Riv Res Appl 26:512-527

Mountford J, Roy D, Cooper J et al (2006) Methods for targeting the restoration of grazing marsh and wet grassland communities at a national, regional and local scale. J Nat Conserv 14:46-66

Mountford JO (1994) Floristic change in English grazing marshes: the impact of 150 years of drainage and land-use change. Watsonia 20:3-24

Nilsson C, Gardfjell M, Grelsson G (1991) Importance of hydrochory in structuring plant communities along rivers. Can J Bot 69:2631-2633

Ockendon N, Thomas DHL, Cortina J, Adams WM, Aykroyd T, Barov B, Boitani L, Bonn A, Branquinho C, Brombacher M, Burrell C, Carver S, Crick HQP, Duguy B, Everett S, Fokkens B, Fuller RJ, Gibbons DW, Gokhelashvili R, Griffin C, Halley DJ, Hotham P, Hughes FMR, Karamanlidis AA, McOwen CJ, Miles L, Mitchell R, Rands MRW, Roberts J, Sandom CJ, Spencer JW, ten Broeke E, Tew ER, Thomas CD, Timoshyna A, Unsworth RKF, Warrington S, Sutherland WJ (2018) One hundred priority questions for landscape restoration in Europe. Biol Conserv 221:198-208

Oksanen J, Blanchet FG, Kindt R, Legendre P, Minchin P, O'Hara R, Simpson G, Solymos P, Stevens H, Wagner H (2012) vegan:community ecology package. R package version 2.0-5. https://CRAN.R-project.org/package=vegan

Pedersen ML, Andersen JM, Nielsen K, Linnemann M (2007) Restoration of Skjern river and its valley: project description and general ecological changes in the project area. Ecol Eng 30:131-144

Pywell RF (2003) Plant traits as predictors of performance in ecological restoration. J Appl Ecol 40:65-77

Reckendorfer W, Baranyi C, Funk A, Schiemer F (2006) Floodplain restoration by reinforcing hydrological connectivity: expected effects on aquatic mollusc communities. J Appl Ecol 43:474-484

Richards DR (2014). Applying an ecosystem service approach to floodplain habitat restoration. Ph.D. Thesis, University of Sheffield

Richards DR, Maltby L, Moggridge HL, Warren PH (2014) European water voles in a reconnected lowland river floodplain: habitat preferences and distribution patterns following the restoration of flooding. Wetl Ecol Manage 22:539-549

Richards DR, Moggridge HL, Maltby L, Warren PH (2018) Impacts of habitat heterogeneity on the provision of multiple ecosystem services in a temperate floodplain. Basic Appl Ecol 29:32-43

Rodwell JS (1991) British plant communities Mires and health, vol 2. Cambridge University Press, Cambridge

Rodwell JS (1992) British plant communities grassland and montane communities, vol 3. Cambridge University Press, Cambridge

Rodwell JS (1995) British plant communities aquatic communities, swamps and tall-herb fens, vol 4. Cambridge University Press, Cambridge

Rohde S, Hostmann M, Peter A, Ewald K (2006) Room for rivers: an integrative search strategy for floodplain restoration. Landsc Urban Plan 78:50-70

Rose F (1981) The wildflower key: British Isles and Northern Europe. Penguin Books, London

Rosenthal G (2006) Restoration of wet grasslands: effects of seed dispersal, persistence and abundance on plant species recruitment. Basic Appl Ecol 7:409-421

Rotherham ID, Harrison K (2006) History and ecology in the reconstruction of the South Yorkshire fens: past, present and future. Proceedings of the IALE conference, water and the landscape: the landscape ecology of freshwater ecosystems, pp 8-16

Schaich H, Rudner M, Konold W (2010) Short-term impact of river restoration and grazing on floodplain vegetation in Luxembourg. Agric Ecosyst Environ 139:142-149

Shaw E (2012) Weir management: challenges, analyses and decision support. PhD Thesis, University of Sheffield

Sozanska-Stanton M, Carey PD, Griffiths GH, Vogiatzakis IN, Treweek J, Butcher B, Charlton MB, Keenleyside C, Arnell NW, Tucker G, Smith P (2016) Balancing conservation and climate change: a methodology using existing data demonstrated for twelve UK priority habitats. J Nat Conserv 30:76-89

Tockner K, Stanford JA (2002) Riverine flood plains: present state and future trends. Environ Conserv 29:308-330

Toogood SE, Joyce CB, Waite S (2008) Response of floodplain grassland plant communities to altered water regimes. Plant Ecol 197:285-298

Toogood SE, Joyce CB (2009) Effects of raised water levels on wet grassland plant communities. Appl Veg Sci 12:283-294

Trowbridge WB (2007) The role of stochasticity and priority effects in floodplain restoration. Ecol Appl 17:1312-1324

Vogt K (2004) Water-borne seed transport and seed deposition during flooding in a small river-valley in Northern Germany. Flora-Morphol Distrib Funct Ecol Plants 199:377-388

Ward JV, Tockner K, Arscott DB, Claret C (2002) Riverine landscape diversity. Freshw Biol 47:517-539

Wheeler BD, Gowing DJG, Shaw SC, Mountford JO, Money RP (2004) Ecohydrological guidelines for lowland wetland plant communities. Environment Agency, Peterborough

Zedler J (2000) Progress in wetland restoration ecology. Trends Ecol Evol 15:402-407

Zsuffa I, Bogardi J (1995) Floodplain restoration by means of water regime control. Phys Chem Earth 20:237-243

Publisher's Note Springer Nature remains neutral with regard to jurisdictional claims in published maps and institutional affiliations. 